\title{
Does the built-environment industry attract risk-taking individuals?
}

Article

Accepted Version

Phua, F. T. T. (2017) Does the built-environment industry attract risk-taking individuals? Construction Management and Economics, 35 (4). pp. 207-217. ISSN 0144-6193 doi: https://doi.org/10.1080/01446193.2016.1237776 Available at https://centaur.reading.ac.uk/68062/

It is advisable to refer to the publisher's version if you intend to cite from the work. See Guidance on citing.

To link to this article DOI: http://dx.doi.org/10.1080/01446193.2016.1237776

Publisher: Taylor \& Francis

All outputs in CentAUR are protected by Intellectual Property Rights law, including copyright law. Copyright and IPR is retained by the creators or other copyright holders. Terms and conditions for use of this material are defined in the End User Agreement.

\section{www.reading.ac.uk/centaur}

\section{CentAUR}

Central Archive at the University of Reading

Reading's research outputs online 


\title{
Does the built-environment industry attract risk-taking individuals?*
}

\begin{abstract}
This exploratory research examines whether or not those attracted to professional-level occupations in the built-environment industry are innately physical risk-takers and hence potentially, thereby, more likely to countenance or contribute to physically risky workplace climates. Using individual-level data, the occupational attractiveness of the built-environment industry subsectors of construction management and architecture are each found positively and significantly to be predicted by physical risk-taking propensity, but not by a comparator risk-taking propensity, gambling. Conversely, the occupational attractiveness of a comparator profession in financial services is found to be significantly predicted by gambling risk-taking propensity, but not by physical risk-taking propensity. Although exploratory, our finding that two key professions in the built-environment industry are each discretely found to be attractive to physical risk-takers suggests not only that constituent occupations within the industry, but that the industry as a whole might perhaps engender a self-reinforcing suboptimal workplace safety climate. Accordingly, constituent subsectors of the industry may need both separately and collectively to consider the phenomenon of physical risk-taking propensity amongst the professionals it attracts in order effectively to set and manage the site work-place safety climate that such professionals are ultimately responsible for creating and delivering in a sector fraught with physical risks for site workers.
\end{abstract}

Key words: Construction management, architecture, occupational attraction, physical risk propensity, gambling risk propensity.

* Three anonymous referees, Roine Leiringer and Will Hughes are thanked for their helpful comments and/or assistance in the review process of this paper. 
Risk-taking $-2^{\text {nd }}$ Revision. Page 2 


\section{Introduction}

The relatively high workplace accident and fatality rates of the built-environment industry globally are often ascribed to the intrinsically physically risky nature of some construction activities (e.g. Sherratt, 2014; Hu et al., 2011; Donaghy, 2009). Considerable research has been geared to understanding the workplace safety climate of the builtenvironment industry (Edwards et al., 2013; Lingard et al., 2010; Hudson, 2007; Siu et al., 2004; Cooper, 2000; Dedobbeleer and Beland, 1991), and several studies have been oriented towards mitigating workplace physical risk through the development of safety standards, and through the systematic derivation of health and safety procedures that professional-level managers are ultimately responsible for designing, instituting, monitoring and enforcing (Kaskutas et al., 2013; Aires et al., 2010; Meldrum et al., 2009; Hopkins, 2009). However, there does not yet appear to have been any scholarly consideration of whether or not the builtenvironment industry might attract professional-level managers who are themselves physical risk-takers who, in consequence, may perhaps have suboptimal approaches to the work-place safety climate they are ultimately responsible for engendering to ensure site workers' physical wellbeing.

There is little question that aspects of the built-environment industry are fraught with physical risk. There is also little question that the work-place safety climate of the industry, for which above all others professional-level managers are answerable, is currently unsuccessful in fully mitigating such risk. If the work-place safety climate was successful, then there would be little question that the UK construction industry, for example, would not account for 31\% of all UK workplace fatal in 2014 despite it employing only 5\% of the UK workforce, (Health and Safety Executive, 2015). There is also little question that individuals’ personalities give rise to differing propensities for risk-taking (Blais and Weber, 2006; Weber et al., 2002), with scholars long suggesting a link between occupation choice and risk-taking aspects of personality (Morris, 1966). 
However, what is open to question is whether or not the built-environment industry might itself actually appeal to professional-level managers with elevated physical risk-taking propensities that might, as a result, perhaps dispose them to underestimate or overlook workplace hazard in their own work or risky practices and behavior amongst the site contractors, trades, and workers for which they have a duty of care. Certainly no research appears yet to have sought to address the possibility that the professionals ultimately responsible for built-environment workplace safety climates might themselves innately be physical risk takers. Getting an answer to this question is important as a recent meta-analysis (Beus et al., 2015) of 69 studies linking personality characteristics like risky sensationseeking and occupational accidents suggests risk-taking propensity is a consistent predictor of a poor workplace safety climate. Our research seeks to address this important question by examining the extent to which individuals attracted to professional-level management occupations within the built-environment industry are both (i) themselves intrinsically risktakers in the domain of physical as opposed to other domains of risk, and (ii) are different in their physical risk-taking propensity compared to those attracted to other professional sectors.

\section{Occupation choice and risk-taking propensity}

Individuals’ occupation choices and their risk-taking propensity have often intuitively been considered related. What little systematic research has been done on this intuitive supposition has generally produced empirical evidence supporting a link between occupation choice and risk-taking propensity. Half a century ago Morris (1966) provided early supportive data on the phenomenon, and Douce and Hanson (1990) subsequently offered sexspecific evidence of a link between risk-taking propensity and occupation choice amongst females. More recent research (Pfeifer, 2011; Roszkowski and Grable, 2009) finds empirical support for the long-held presumption that public sector employees have lower risk-taking propensities than private sector employees. 
Notwithstanding some evidence of a link between occupation choice and risk-taking propensity, research on this link has broadly remained at a general rather than specific level. This generality applies in terms of both occupation and risk-taking specificity.

In relation to occupation, occupational categories have usually been specified in very broad terms, such as informal versus formal occupations (Falco, 2014), stable- versus unstable-earnings occupations (Bonin et al., 2007), or the public versus private sector occupational split (Buurman et al., 2012). Certainly no research appears to have been done on risk-taking propensity and the occupational attractiveness of either the built-environment industry broadly or, more narrowly, the respective subsectors of which the industry comprises.

In relation to risk-taking propensity, this has often been conceptualized and measured as a general tendency to take risks. The underlying conceptual presumption here is that risktaking propensity is a personality characteristic that will manifest itself in risk-taking behaviours across all areas where risk occurs, be those areas in gambling, investment, social, health or other life domains. Research on generalized risk-taking has been facilitated by the availability of metrical tools to assess its extent. For example, Steketee and Frost (1994) developed the Everyday Risk Inventory to measure, as its name implies, a very generalized risk-taking propensity; and Meertens and Lion (2008) have more recently developed the Risk Propensity Scale to measure a similarly generalized risk-taking tendency.

However, the practical usefulness of assuming generalized risk-taking is stable and constant across all life domains has long been questioned (see Fox and Tannenbaum (2011) for a review). Risk-taking propensity has also been conceptualized as relating to, and differing by, specific risk domains (see Harrison et al., 2005 for a review). For instance, Weber et al. (2002) theorized and developed a scale measuring risk-taking propensity in terms of, respectively, financial decisions, health, recreation, ethics and social domains of 
life. Rohrmann (2002), too, has developed somewhat overlapping scales covering financial, health, social, and particularly pertinently for our purposes, physical risk-taking propensity.

Building on these more fine-grained conceptualizations of risk-taking propensity, Deck et al., (2014) demonstrate that, respectively, investment and gambling risk behaviour are differentially predicted by different risk-taking propensities, suggesting that the links between occupation choice and risk-taking propensity may need to be examined at a less general and altogether more nuanced level than has hitherto been the case. Given this, we suggest it would be reasonable to make the following three broad speculations in relation to the built-environment industry.

First, we speculate that the professional-level occupational attractiveness of the builtenvironment industry may be differentially predicted by discrete forms of risk-taking propensity. The generally known physically hazardous nature of some aspects of the builtenvironment industry highlighted in research by Sherratt (2014) and others might reasonably be expected to make the industry occupationally attractive to professional-level managers with higher physical risk-taking propensities. However, there would seem to be no immediately apparent characteristics of the built-environment industry that would make it more attractive to those with risk-taking propensities in other domains. For example, there is no obvious reason why gambling risk-taking propensity might predict built-environment occupational attractiveness for professional-level managers.

Second, we speculate that the professional-level occupational attractiveness of distinct built-environment industry subsectors may be predicted differentially by discrete forms of risk-taking propensity. Some aspects of the built-environment industry are necessarily more physically risky than others. The construction management subsector broadly, because it usually demands extensive onsite working, is perhaps more exposed to physical risks than, for example, architecture. While architects do sometimes get involved in onsite working, the occupation generally requires considerably less onsite working than construction 
management. It would therefore seem reasonable to speculate that the construction management subsector may be predicted by physical risk-taking propensity, whereas the architecture subsector will either be less strongly, or indeed be unpredicted, by physical risktaking propensity. Combing our first and second speculations here, we suggest these specific propositions:

\section{P1. The construction management subsector's} occupational attractiveness will be predicted by physical risk-taking propensity.

P2. Gambling risk-taking propensity will not predict the construction management subsector's occupational attractiveness.

P3. The architecture subsector's occupational attractiveness will be predicted less strongly, or not at all, by physical risk-taking compared to the construction management subsector.

P4. Gambling risk-taking propensity will not predict the architecture subsector's occupational attractiveness.

Third, we speculate that the professional-level occupational attractiveness of builtenvironment industry subsectors may be differently predicted by discrete risk-taking propensities compared to other professional-level occupational areas. For example, while we cannot readily identify substantive reasons to suppose individual built-environment subsectors’ occupational attractiveness might be predicted by gambling risk-taking propensity, the same cannot be said for some other professional sectors, such as in financial services. Of course, some subcontractors in the construction industry have been identified as making speculative bids for contracts (Hinton \& Hamilton, 2016). But such bidding is common to all industries where contract bidding occurs and is neither gambling in the 
generally accepted sense or a defining characteristic of the built environment industry as a whole.

By contrast, one sector of the financial services industry, the banking sector specifically, has been characterized by scholars as having an inherently gambling-like culture (McDowell, 2010), with modern banking often described as ‘casino capitalism’ (Strange, 1997). Indeed, Nobel Prize-winning economists conclude that the regulatory and competitive banking environment prevailing in recent decades 'tends to promote gambling in the banking sector’ (Hellmann, Murdock \& Stiglitz, 2000, p. 149), and a considerable stream of scholarly research has been devoted to investigating what is an acknowledged and entrenched gambling facet of the banking profession (see for example Aikman, Nelson \& Tanaka, 2015; Dam, Escrihuela-Villar \& Sanchez-Pages, 2015; Niu, 2008; Repullo, 2004; Vo, 2015).

Given this, banking might be speculated to be occupationally attractive to those with a gambling risk-taking propensity. However, the banking sector's freedom from apparent or plausible physical hazards would suggest no obvious attraction to those who are physical risk-takers, hence:

P5. The banking sector's occupational attractiveness will be predicted by gambling risk-taking propensity.

P6. Physical risk-taking propensity will not predict the banking sector's occupational attractiveness.

\section{Methods}

Participants and procedure

To enable us to compare both built-environment-related and non-built-environmentrelated sectors' occupational attractiveness, we sought to sample a broad cross-section of the working age population. We also sought to eliminate potential confounding effects of national culture that have been linked to risk-taking propensity by confining our sample to a 
single country (see Knuth et al., 2014 and Rohrmann, 1994). Accordingly, a sample of 2000 was drawn from a larger and broad sample of United Kingdom citizens who had volunteered to assist with scholarly research. Using random number seeding for cases, we sought to derive a random but stratified sample. We specifically sought to obtain a sample with a balance between those already working and those still students yet to enter the workforce so we could control for potential effects of occupational experience on both occupational attractiveness and risk-taking propensities. We also sought a balanced sample in terms of sex, education, and age. Hence, procedurally, we ensured that half our sample already worked, that half of those in each of the two respective worker/student cells were male, and that half of both males and females in each of the four subsequent cells had tertiary education, and that in each of the subsequent eight cells a reasonable cross-section of ages was represented. An online instrument was designed, pilot-tested and then administered by email.

An initial administration was followed-up by a reminder one month later, producing a final sample of 602 fully completed responses. After eliminating respondents who stated their occupation as retired or full-time house-wife/husband, our useable sample was 554 . While this represented a respectable response rate of around 28 percent from our original sample, we nevertheless tested for potential unit non-response bias using Armstrong and Overton’s (1977) procedure for comparing early and late responders. We found no significant differences between initial and reminder emailing respondents with respect to age $\left(\chi^{2}=\right.$ 11.16, $p=.52)$, sex $\left(\chi^{2}=0.08, p=.77\right)$, education $\left(\chi^{2}=0.02, p=.88\right)$, or occupation $\left(\chi^{2}=\right.$ $0.14, p=.69)$, suggesting unit non-response bias is not manifestly evident in the obtained sample. 
Dependent variables. To ensure respondents had a reasonably uniform and accurate conception of each occupation, succinct and deliberately anodyne lay descriptors for each were given prior to assessing occupational attractiveness (e.g. architecture is the design of buildings). We followed Courtright and Mackey (2004) in assessing occupational attractiveness by using a continuous measure. However, unlike these researchers, we did not use a single item, but instead used a 5-item scale to obtain higher validity and reliability. Sector occupational attractiveness was assessed for, respectively, the construction management, architecture, and banking sectors with a question whose stem asked: 'Regardless of your current occupation, how true for you personally is it that a career in the (sector name) sector would be ...?’ Five items then followed: Unpleasant, Enjoyable, Unattractive, Desirable, and Dislikable. The mixed positive and negative valences of items was designed to reduce response set and acquiescence responding (Knowles and Nathan, 1997). These items were answered on a 6-point interval measure running: Very Untrue, Untrue, Slightly Untrue, Slightly True, True, Very True. To help reduce method variance (Spector, 2006), questions for each sector were dispersed throughout the instrument rather than presented as a block. Negatively valenced items were reverse-coded and a summated mean was then derived for each occupation. The Cronbach's alphas for internal consistency reliability of each sectors' occupational attractiveness are: construction management $\alpha .85$, architecture $\alpha .83$, and banking $\alpha .79$.

Independent variables. We drew directly on the two most frequently deployed, most systematically derived and validated self-report measures of domain-specific risk-taking propensity, Rohrmann’s (2002) Risk Attitude Scales and Weber et al’s (2002) Domainspecific Risk-Attitude Scale, as the basis for our measures of, respectively, physical and gambling risk-taking. Both Rohrmann’s (2002) and Weber et al's (2002) measures were developed using student samples, and have some items that are specific to either the Australian or North American contexts in which they were respectively developed. 
Consequently we modified some items to make them applicable to a more general and UKspecific population. Following Weber et al (2002), the question stem for both physical and gambling risk propensity was 'How likely or unlikely is it that you personally would do the following?’ This was followed by, for the physical risk items: Rock climbing, Sky diving, Bungee jumping, Hang-gliding; and for the gambling risk propensity items: Gamble one week’s income at a casino, Bet four day's income on a horse race, Spend a month's income on lottery tickets, Gamble two week’s income on a football match. Physical and gambling risk propensity items appeared alternately to reduce method variance and were answered on a 6-point interval measure running: Very Unlikely, Unlikely, Slightly Unlikely, Slightly Likely, Likely, Very Likely. Table 1 has results of a factor analysis of the items that shows they produce a bi-dimensional solution with extremely low cross-loadings, indicating two things: First, that risk propensities for physical and gambling risks are discrete and respectively unidimensional constructs. Second, that our data suffer from little, if any, substantive method variance. The Cronbach’s alphas of internal consistency reliability are $\alpha .88$ for physical risk propensity and $\alpha .86$ for gambling risk-taking propensity.

\section{Control variables}

Age. Risk-taking has been demonstrated to differ by age due both to socialization effects (Rolison et al., 2014) and to altered neural processes over time (Lee et al., 2008), with most forms of risk-taking propensity generally declining with age (Weller et al., 2011). Accordingly, we controlled for age. Due to the reluctance of some people to give their exact age, rather than lose usable responses through item non-response we measured age in categories of 5-year blocks that are less off-putting to complete. Mode age for our sample is 25-29 years (32.3 percent), with 29.2 percent aged 20-24 years, 12.6 percent 30-34 years, 6.9 percent 35-39 years, 17.9 percent in the 5-year categories between 40 and 69 years, with the remainder 15-19 year olds. Rather than code categories from 1 to 11 and thereby provide a continuous measure for age based on 5- rather than 1-year age units, we created 5 dummy 
variables by collapsing the 5-year into 10-year categories. This meant eliminating the 15-19 year old category to ensure comparable year-spans in each category, so our sample thereby reduced by 6 to 548 .

Sex. Prior research on the effect of sex on risk-taking finds support for differences between males and females across different domains of risk behaviours (Charness and Gneezy, 2012; Knuth et al., 2014; Lam and Ozorio, 2013). Hence we controlled for sex, with our dummy coded 1 for males. Our sample comprises 55.8 percent females, offering a reasonable balance between the sexes.

Education. Level of formal education has been found to influence risk-taking behaviour across a range of job functions (Knight et al., 2003; Wang, et al., 2013). Therefore we controlled for education level. We collected data on highest level of educational attainment, allowing us to collapse bachelor, master and doctoral degree qualifications into a single category of tertiary education thereby producing a tertiary/non-tertiary education dummy, with tertiary education attainment coded 1 . Reflecting our efforts to draw an original sample comprising a balance between those with and without tertiary education, some 48.5 percent of our final sample has attained a tertiary education qualification.

Student. We wanted to control for possible effects of having already entered the workforce on both occupational attractiveness and risk-taking propensity. Hence, we asked respondents to give their current occupations in order to create a dummy variable for students/non-students (and to eliminate retirees/house-wives/husbands). Non-students comprise 54 percent of our final sample. Non-students comprise public sector employees (21.3 percent of the total sample), private firm employees (23.6 percent), selfemployed/business owners (9.2 percent), with the remainder unemployed. We collapsed the non-students into one category to create a dummy with student coded 1.

Social desirability. Both our dependent and independent variables could each potentially be susceptible to socially desirable responding. Hence we controlled for social 
desirability using a short-form of Crowne and Marlowe’s (1960) measure developed by Strahan and Gerbasi (1972) and more recently modified by Thompson and Phua (2005). Similarly to these latter researchers, we find the scale’s Chronbach's alpha of internal consistency reliability to be modestly acceptable at .67.

\section{Analyses and Results}

Table 2 shows descriptive statistics. The low inter-item correlations amongst the control and independent variables indicate multicollinearity not to be a problem. Table 3 shows regressions for each sector’s occupational attractiveness.

Model 1 provides a baseline model predicting the construction management subsector’s occupational attractiveness using control variables alone. Model 2 enters both physical and gambling risk-taking propensities, along with controls. This reveals that physical but not gambling risk-taking propensity positively and significantly predicts construction management occupational attractiveness, and that the percentage of additional variance explained in construction management occupational attractiveness by including physical risk-taking propensity is significant. This finding tends to support our propositions that construction management is attractive to individuals with higher physical, but not gambling, risk-taking propensities.

Model 3 provides a baseline model predicting the architecture subsector's occupational attractiveness using controls alone, with the model proving to be insignificant. Model 4 enters both physical and gambling risk-taking propensities along with controls. Physical, but not gambling risk-taking propensity, positively and significantly is found to predict architecture occupational attractiveness, and the overall percentage of variance explained in architecture occupational attractiveness by physical risk-taking propensity is significant. Indeed, the change in variance explained in architecture's occupational attractiveness by the addition of physical risk-taking is larger than that for construction 
management's occupational attractiveness. Hence our proposition that the occupational attractiveness of the architecture subsector will be either weakly or not predicted by physical risk-taking propensity is unsupported, although our proposition that gambling risk-taking will not predict architecture's occupational attractiveness is borne out.

Model 5 shows that gambling, but not physical, risk-taking propensity positively and significantly predicts banking attractiveness. This thereby supports our propositions that banking's occupational attractiveness would be unlike, and opposite to, the builtenvironment's.

\section{Discussion and conclusions}

While this is a small-scale exploratory study with several limitations that need to be acknowledged and addressed in future research (see below), our findings are of a size and statistical significance that some initial observations are warranted.

Overall, our findings lend support to our broad speculation that the occupational attractiveness of the built-environment industry at a professional-level might be predicted by physical risk-taking propensity, but not other domains of risk-taking propensity, our specimen comparator here being gambling risk-taking propensity. Moreover, our finding that the occupational attractiveness of the comparator profession of banking is predicted by gambling, but not physical, risk-taking propensity supports our speculation that physical risktaking propensity might predict built-environment industry occupational attractiveness while not playing a similar predictive role across all professions. There are possibly other industry sectors that might also attract professionals with a physical risk-taking propensity, but our finding here suggests the built-environment industry itself has, albeit perhaps not uniquely, a specific problem with which researchers and practitioners might usefully to engage.

A particularly intriguing, and possibly worrying, aspect of our findings, is that not just construction management but also the architecture subsector seems, contrary to our 
expectation, to attract physical risk-takers. Our speculation that different subsectors of the built-environment industry might be differentially predicted by physical risk-taking propensity was not supported, at least so far as architecture is concerned. Our finding here could reflect that the architecture profession specifically is, contrary to our own view, regarded popularly as equally or even more physically risky than construction management. Architects do, after all, get involved in project management. Alternatively, some other facet of architecture might be attractive to physical risk-takers. Determining why architecture appears attractive to physical risk-takers is clearly a matter for further research. However, and this really would prove worrying for the built-environment industry, perhaps there is nothing uniquely peculiar about architecture and, in fact, all the subsectors of the built-environment may somehow be viewed popularly as subordinate to, or indivisible from, the larger industry they constitute and be, therefore, attractive to physical risk-takers. Whether additional, more extensive and more fine-grained research finds it is just construction management and architecture, or all subsectors of the built environment industry, that attract physical risktakers, our results here suggest an overt effort to consider the possible effects of professionallevel physical risk propensities throughout the industry might be useful.

Given our current understanding of the causal link between design and construction in accidents and fatalities prevention (Larsen and Whyte, 2013; Atkinson and Westall, 2010; Behm, 2005), it makes practical sense for architectural firms to exercise due regard relating to individual risk-taking propensities in their selection, hiring and training practices. Indeed, all aspects of management, process and procedure in both the construction management and architecture subsectors could usefully benefit from heightened awareness of, and adaptation to, the higher levels of physical risk-taking that appears to predict attractiveness to both of them as occupations.

If further research finds other professional-level built-environment industry subsectors that, like architecture, are ostensibly unlikely to attract physical risk-takers but in fact do 
attract them, then the useful check that might otherwise be provided by architecture and other subsectors on physical risk-taking propensity elsewhere within the industry is simply not there. Moreover, if additional research finds that contractor-, trade- and worker-level occupations similarly attract physical risk-takers, potentially the whole built-environment industry collectively may be inadequately conscious of physical risks. Hence, the industry as a whole at all levels may fail to design into procedures and practices the kind of measures necessary to mitigate physical hazards. Indeed, if all parties and team members in builtenvironment projects are found to tend to have elevated physical risk-taking propensities, then the industry as a whole might suffer from a form of self-reinforcing suboptimality of workplace safety climate. Such a speculation would seem entirely consonant with the disproportionately high share of workplace injuries and fatalities currently witnessed in the built-environment industry.

Should further research find this to be the case, then addressing the issue would require not just a subsector by subsector approach, but a built-environment industry-wide approach to mitigating the effects of dangerous physical risk-taking propensity. Certainly, research on behaviourally-based management techniques such as goal-setting and feedback interventions for both site operatives and managers (Cameron and Duff, 2007; Duff et al., 1994; Lingard and Rowlinson, 1998) to improve safety performance might usefully take into account the effects of individuals’ physical risk-taking propensities.

Doing this will likely require the incorporation of an understanding of the elevated physical risk-taking propensity of those attracted to each subsector that permeates all aspects of each. This might most appropriately start with education and training where physical risk, and its subsequent dangers, could perhaps feature as a more prominent element of curricula, both for study prior to entering the profession and then subsequent on-the-job training and professional development qualifications. Recruitment into both subsectors might also usefully seek to assess individual levels of physical risk-taking propensity so that due consideration of 
this can be used in hiring and career development decisions. This is perhaps particularly relevant in construction management where even at relatively high levels of practical management responsibility, some recruitment remains relatively informal and even onsite with long-noted ‘wider deleterious consequences’ (Bresnen et al., 1986, p.37), not least from a safety perspective.

\section{Limitations}

Although our data support our broad speculations by finding that two subsectors of the built-environment industry are occupationally attractive to physical, but not gambling risk-takers, whereas the banking profession is attractive to gambling, but not, physical risktakers, our study has limitations. And it suggests several avenues for more extensive research. Clearly, we only address two discrete built-environment industry subsectors. Further research that looks at the occupational attractiveness of more subsectors will be illuminating, as will additional research that attempts to decompose both the construction management and architecture subsectors into discrete and more nuanced areas. Moreover, we have only examined professional occupations in the built-environment industry. While these professions are of prime importance in setting an overall framework for workplace safety climate, the unfortunate results of physical risk taking are most frequently manifested amongst contractors, subcontractors, trades and workers. The widespread use of casual, migrant, or even volunteer workers in these contexts has given cause for many safety concerns (Sherratt et al., 2015; Tutt et al., 2013; Mayhew et al., 1997). Hence, particularly useful to examine might be the physical risk-taking propensity of various trades amongst contractors and subcontractors, such as scaffolders (Zhang and Fang, 2013) and masons (Memarian and Mitropoulos, 2013), for example. If the majority of built-environment industry nonprofessional subsectors are also found to attract workers who are physical risk-takers, then our point about the industry as a whole suffering from a form of self-reinforcing suboptimal 
safety environment stemming from physical risk-taking propensity would gain added traction, as would the need to address such a reality.

A further area of research might address the extent to which level of managerial seniority or closeness to direct and formal responsibility for ensuring safety within the builtenvironment industry is related to physical risk-taking propensity. In the event more senior managers or those with more extensive overt responsibility for safety are found to have elevated physical risk-taking propensities, then this would signal a serious concern that would need serious efforts to address within the industry.

Methodologically, while our sample is not small, it has several constraints. Our respondents are all (deliberately) British, and they are more highly educated than the norm for the British population. Further research using larger, more international, and more representative samples would be useful. Additionally, we sampled a relatively broad population. Further research on physical risk-taking propensity specifically amongst those already working within the built-environment industry could prove illuminating. Moreover, while we sought to control for, but made no hypotheses regarding, age, further research might seek to incorporate more specific consideration of how age could either mediate or moderate physical risk-taking propensity. In similar vein, although we deliberately sought to control for social desirability, we did not attempt to control for specific attitudes towards risks, either gambling or physical, that might perhaps be determined by cultural, social, religious and other factors. Further research could possibly attempt to incorporate measures to address such attitudes.

Despite our results showing that two built-environment industry subsectors’ occupational attractiveness' are predicted by physical risk-taking propensity, whereas this is not the case for the comparator profession of banking, there is always the possibility, however slight, that our selected comparator sector is unique, or indeed that our selected comparator risk-taking propensity of gambling produces aberrant results. Hence, further 
research might perhaps seek to examine other comparator sectors’ occupational attractiveness in relation to physical, gambling and other risk-taking propensities. Moreover, because the field of individual risk-taking is a developing one, our conceptual and measurement approach to risk-taking propensity could, perhaps and despite our having followed the most welldeveloped and validated work in the area, be superseded by future theoretical and metrical developments that produce dissimilar results to our own here.

\section{Conclusions}

Limitations aside, our research provides the first systematic attempt to propose and examine the relationship between the occupational attractiveness of the built-environment industry and physical risk-taking propensity. Our findings suggest that the occupational attractiveness of the two key industry subsectors of construction management and architecture are predicted by individual physical risk-taking propensity. By contrast, we find that a comparator profession's attractiveness, banking, is not predicted by physical risktaking propensity, although it is predicted by gambling risk-taking, unlike either construction management or architecture.

That we somewhat unexpectedly found architecture in addition to construction management is an occupation attractive to physical risk-takers raises the possibility that the built-environment as a whole might be attractive to individuals with elevated levels of physical risk-taking propensity. Should additional necessary research find this indeed to be the case, the industry as a whole will need collectively to address how to incorporate this reality into its processes and procedures. As it is, our findings indicate that the construction management and architecture subsectors individually and jointly need already to investigate further physical risk-taking propensity amongst those attracted to each profession. And, crucially, these two subsectors need to begin now to search for ways to mitigate any adverse effects on workplace safety climate of them each respectively attracting physical risk-takers. 
Clearly, more extensive, more fine-grained, and more nuanced research at a scholarlylevel is required, and effective cognizance of our own and subsequent research findings in this area needs to be reflected at a practitioner-level. Poor workplace safety climate may manifest itself at the contractor-, trade- and worker-levels, but it is, ultimately, a top-down matter: Professional occupations in the built-environment industry are directly responsible for understanding and managing all the facets of the industry and all that affects those facets, especially workplace safety climate. If a fuller understanding of individual physical risktaking potential, both throughout the industry and at professional and other levels, can assist in developing better workplace safety climates, then scholars would seem to have a useful role in developing our own exploratory research here into a fuller, more extensively theorized, and data-rich ongoing research agenda.

\section{References}

Aikman, D.; Nelson, B. \& Tanaka, M. (2015). Reputation, risk-taking, and macroprudential policy. Journal of Banking \& Finance. 50, 428-439.

Aires, M.D.M., Gámez, C.R. and Gibb, A. (2010) Prevention through design: The effect of European Directives on construction workplace accidents. Safety Science, 48(2), 248258.

Armstrong, J.S. and Overton, T.S. (1977) Estimating nonresponse bias in mail surveys. Journal of Marketing Research, 14(3), 396-402.

Atkinson, A.R. and Westall, R. (2010) The relationship between integrated design and construction and safety on construction projects. Construction Management and Economics, 28(9), 1007-1017.

Behm, M. (2005) Linking construction fatalities to the design for construction safety concept. Safety Science, 43(8), 589-611.

Beus, J.M., Dhanani, L.Y. and McCord, M.A. (2015) A meta-analysis of personality and 
workplace safety: addressing unanswered questions. Journal of Applied Psychology, 100(2), 481-498.

Blais, A. E. and Weber, E U. (2006) A Domain-Specific Risk-Taking (DOSPERT) scale for adult populations. Judgment and Decision Making, 1(1), 33-47.

Bonin, H., Dohmen, T., Falk, A., et al. (2007) Cross-sectional earnings risk and occupational sorting: The role of risk attitudes. Labour Economics,14(6), 926-937.

Bresnen, M.J., Ford, J. R., Bryman, A. E., Keil, E. T., Beardsworth, A. D. and Wray, K. (1986) Labour recruitment strategies and selection practices on construction sites, Construction Management and Economics, 4(1), 37-55.

Buurman, M., Delfgaauw, J., Dur, R. and van den Bossche, S. (2012). Public sector employees: Risk averse and altruistic?, CESifo Working Paper: Behavioural Economics, No. 3851

Cameron, I. and Duff, R. (2007) Use of performance measurement and goal setting to improve construction managers' focus on health and safety. Construction Management and Economics, 25(8), 869-881.

Charness, G. and Gneezy, U. (2012) Strong evidence for gender differences in risk. Journal of Economic Behavior \& Organization, 83(1), 50-58.

Cooper, M. (2000) Towards a model of safety culture. Safety Science, 36(2), 111-136.

Courtright, K. E. and Mackey, D. A. (2004) Job desirability among criminal justice majors: exploring relationships between personal characteristics and occupational attractiveness. Journal of Criminal Justice Education, 15, 311-326.

Crowne, D. P. and Marlowe, D. (1960) A new scale of social desirability independent of psycho-pathology. Journal of Consulting Psychology, 24, 349-354.

Dam, K., Escrihuela-Villar, M. \& Sanchez-Pages, S. (2015). On the relationship between market power and bank risk taking. Journal of Economics. 114, 177-204.

Deck, C., Lee, J. and Reyes, J. (2014) Investing versus gambling: experimental evidence of 
multi-domain risk attitudes. Applied Economic Letters, 21(1), 19-23.

Dedobbeleer, N. and Beland, F. (1991) A safety climate measure for construction sites. Journal of Safety Research, 22(2), 97-103.

Donaghy, R. (2009) One Death Is Too Many - Inquiry into the Underlying Causes of Construction Fatal Accidents, The Stationery Office, Norwich.

Douce, L. A., \& Hansen, J. C. (1990). Willingness to take risks and college women's career choice. Journal of Vocational Behavior, 36, 258-273.

Duff, A.R., Robertson, I.T., Phillips, R.A. and Cooper, M.D. (1994) Improving safety by the modification of behaviour. Construction Management and Economics, 12(1), 67-78.

Edwards, J.R.D., Davey, J. and Armstrong, K. (2013) Returning to the roots of culture: A review and re-conceptualisation of safety culture. Safety Science, 55(1), 70-80.

Falco, P. (2014) Does risk matter for occupational choices? Experimental evidence from an African labour market. Labour Economics, 28(1), 96-109.

Fox, C.R. and Tannenbaum, D. (2011). The elusive search for stable risk preferences. Frontiers in Psychology, 2 (298) (2011), pp. 1-4.

Harrison, J. D., Young, J. M., Butow, P., Salkeld, G., \& Solomon, M. J. (2005). Is it worth the risk? A systematic review of instruments that measure risk propensity for use in the health setting. Social Science \& Medicine, 60, 1385-1396.

Health and Safety Executive (2015). Health and safety in construction in Great Britain, 2014/15, The Health and Safety Executive, http://www.hse.gov.uk/statistics/industry/construction/construction.pdf Accessed 6 April 2016.

Hellmann, T.F.; Murdock, K.C.; Stiglitz, J.E. (2000). Liberalization, moral hazard in banking, and prudential regulation: Are capital requirements enough? American Economic Review. 90, 147-165.

Hinton, M.A. \& Hamilton, R.T. (2016). Competitive tendering and individual behaviour in 
the construction industry: convenient immorality at work. Construction Management and Economics, 34, 880-889.

Hopkins, A. (2009) Thinking about process safety indicators. Safety Science, 47, 460-465.

Hu, K., Rahmandad, H., Smith-Jackson, T. and Winchester, W. (2011) Factors influencing the risk of falls in the construction industry: a review of the evidence. Construction Management and Economics, 29(4),,397-416.

Hudson, P. (2007) Implementing a safety culture in a major multi-national. Safety Science, 45(6), 697-722.

Kaskutas, V., Dale, A.M., Lipscomb, H., and Evanoff, B. (2013) Fall prevention and safety communication training for foremen: report of a pilot project designed to improve residential construction safety. Journal of Safety Research. 44, 111-118.

Knight, J., Weir, S. and Woldehanna, T. (2003) The role of education in facilitating risktaking and innovation in agriculture. Journal of Development Studies, 39(6), 1-22.

Knowles, E.S. and Nathan, K.T. (1997) Acquiescent responding in self-reports: Cognitive style or social concern? Journal of Research in Personality, 31(2), 293-301.

Knuth, D., Kehl, D., Hulse, L., et al. (2014) Risk perception, experience, and objective risk: A cross-national study with European emergency survivors. Risk Analysis, 34(7), 1286-1298.

Lam, D. and Ozorio, B. (2013) The effect of prior outcomes on gender risk-taking differences. Journal of Risk Research, 16(7), 791-802.

Larsen, G. D. and Whyte, J. (2013) Safe construction through design: perspectives from the site team. Construction Management and Economics, 31(6), 675-690.

Lee, T. M. C., Leung, A. W. S., Fox, P. T., et al. (2008) Age-related differences in neural activities during risk taking as revealed by functional MRI. Social Cognitive and Affective Neuroscience, 3(1), 7-15.

Lingard, C. H., Cooke, T. and Blismas, N. (2010) Properties of group safety climate in 
construction: the development and evaluation of a typology. Construction Management and Economics, 28(10), 1099-1112.

Lingard, H. and Rowlinson, S. (1998) Behaviour-based safety management in Hong Kong’s construction industry: the results of a field study. Construction Management and Economics,16(4), 481-488.

Mayhew, C., Quintan, M. and Ferris, R. (1997) The effects of subcontracting/ outsourcing on occupational health and safety: Survey evidence from four Australian industries. Safety Science, 25(1-3), 163-178.

McDowell, L. (2010) Capital culture revisited: sex, testosterone and the City. International Journal of Urban and Regional Research, 34(3), 652-658.

Meertens, R. M., \& Lion, R. (2008). Measuring and individual's tendency to take risks: The risk propensity scale. Journal of Applied Social Psychology, 38(6), 1506-1520.

Meldrum, A., Hare, B. and Cameron, I. (2009) Road testing a health and safety worker engagement tool-kit in the construction industry. Engineering, Construction and Architectural, Management, 16(6), 612-632.

Memarian, B. and Mitropoulos, P. (2013) Accidents in masonry construction: The contribution of production activities to accidents, and the effect on different worker groups, Safety Science, 59, 179-186.

Morris, J. L. (1966). Propensity for risk taking as a determinant of vocational choices. Journal of Personality and Social Psychology, 3, 328-335.

Niu, J. (2008). Bank competition, risk, and subordinated debt. Journal of Financial Services Research. 33, 37-56.

Pfeifer, C. (2011) Risk aversion and sorting into public sector employment. German Economic Review,12(1) 85-99.

Repullo, R. (2004). Capital requirements, market power, and risk-taking in banking. Journal of Financial Intermediation. 13, 156-182. 
Rohrmann, B. (1994) Risk perception of different societal groups: Australian findings and cross-national comparisons. Australian Journal of Psychology, 46, 150-163.

Rohrmann, B. (2002) Risk Attitude Scales: Concepts and questionnaires. Project Report University of Melbourne/Australia - Nov. www.rohrmannresearch.net/pdfs/rohrmannras-report.pdf

Rolison, J. J., Hanoch, Y., Wood, S., et al. (2014) Risk-Taking differences across the adult life span: A question of age and domain. Journals of Gerontology Series BPsychological Sciences and Social Sciences, 69(6), 870-880.

Roszkowski, M.J., Grable, J.E., 2009. Evidence of lower risk tolerance among public sector employees in their personal financial matters. Journal of Occupational and Organizational Psychology 82(2), 453-463.

Sherratt, F. (2014) Exploring 'zero target' safety programmes in the UK construction industry. Construction Management and Economics, 32(7-8), 737-748.

Sherratt, F., Crapper, M., Foster-Smith, L. and Walsh, S. (2015). Safety and volunteer construction workers, Construction Management and Economics, 33(5-6), 361-374.

Siu, O., Phillips, D.R. and Leung, T. (2004) Safety climate and safety performance among construction workers in Hong Kong: the role of psychological strains as mediators. Accident Analysis and Prevention, 36, 359-366.

Spector, P.E. (2006) Method variance in organizational research - Truth or urban legend? Organizational Research Methods, 9(2), 221-232.

Steketee, G. and Frost, R.O. (1994) Measurement of risk-taking in obsessive-compulsive disorder. Behavioral and Cognitive Psychotherapy, 22, 287-298.

Strahan, R. and Gerbasi, K. C. (1972) Short, homogeneous versions of the Marlow-Crowne social desirability scale. Journal of Clinical Psychology, 28, 191-193.

Strange, S. 1997. Casino Capitalism. London: Basil Blackwell.

Thompson, E.R. and Phua, F.T.T. (2005) Reliability among senior managers of the Marlowe- 
Crowne short-form Social Desirability Scale. Journal of Business and Psychology, 19(4), 541-555.

Tutt, D., Pink, S., Dainty, A.R.J. and Alistair Gibb, A. (2013) 'In the air' and below the horizon: migrant workers in UK construction and the practice-based nature of learning and communicating OHS. Construction Management and Economics, 31(6), $515-527$.

Vo, L.H. (2015). Lessons from the 2008 Global Financial Crisis: Imprudent Risk Management and Miscalculated Regulation. Journal of Management Sciences, 2, 205222.

Wang, Y., Zhou, W. and Chang, K.C. (2013) Effect of decision makers' education level on their corporate risk taking. Social Behavior and Personality, 41(7), 1225-1229.

Weber, E.U., Blais, A.R. and Betz, N.E. (2002) A domain-specific risk-attitude scale: measuring risk perceptions and risk behaviors. Journal of Behavioral Decision Making, 15, 263-290.

Weller, J.A., Levin, I.P. and Denburg, N.L. (2011) Trajectory of risky decision making for potential gains and losses from ages 5 to 85. Journal of Behavioral Decision Making. 24(4), 331-344.

Zhang, M., and Fang D. (2013) A cognitive analysis of why Chinese scaffolders do not use safety harnesses in construction. Construction Management and Economics, 31(3), 207-222. 
Table 1. Factor analysis of the physical and gambling risk propensity measure

\begin{tabular}{lcc}
\hline Scale items & $\begin{array}{c}\text { Physical risk } \\
\text { propensity }\end{array}$ & $\begin{array}{c}\text { Gambling Risk } \\
\text { Propensity }\end{array}$ \\
\hline Sky-diving & $\mathbf{. 9 2}$ & .09 \\
Hang-gliding & $\mathbf{. 8 9}$ & .06 \\
Bungee-jumping & $\mathbf{. 8 8}$ & .12 \\
Rock-climbing & $\mathbf{. 8 1}$ & .01 \\
Gamble two weeks' income on a football match & .04 & $\mathbf{. 9 1}$ \\
Gamble one week's income at a casino & .07 & $\mathbf{. 8 8}$ \\
Bet four days' income on a horse race & .11 & $\mathbf{. 8 6}$ \\
Spend a month's income on lottery tickets & .04 & $\mathbf{. 8 5}$ \\
$\quad$ Eigen value & 3.58 & 2.62 \\
\multicolumn{1}{c}{ Cumulative \% variance explained } & 44.57 & 77.28
\end{tabular}

Note. $N=548$. Loadings from principal component analysis with varimax rotation, sorted by magnitude, significant loadings emboldened. 


\section{Table 2. Means, standard deviations and inter-item correlations}

Inter-item correlations

Dependent Variables

SD

Construction management $\quad 2.59 \quad 1.25$

2. Architecture $\quad 3.18 \quad 1.19$

3. Banking $2.56 \quad 1.29$

Control variables
4. Age 20-29 - $\quad$ - $\quad-.15^{* * *}-.12^{* *}$

5. Age 30-39

6. Age 40-49

7. Age 50-59

8. Age 60-69

9. Sex

10. Education

11. Student

12. Social desirability

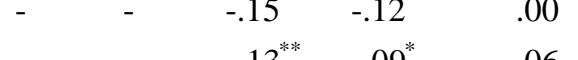
$\begin{array}{llllll}- & - & .13^{* *} & .09^{*} & .06 & -.57^{* * *}\end{array}$

$\begin{array}{lllllll}- & - & .03 & .06 & .01 & -.37^{* * *} & -.15^{* * *}\end{array}$

$\begin{array}{llllllll}- & - & .05 & .02 & -.06 & -.42^{* * *} & -.17^{* * *} & -.11^{*}\end{array}$

$\begin{array}{lllllllll}- & - & .05 & .02 & -.06 & -.42^{* * *} & -.17 & -.11 & \\ - & - & -.02 & .02 & -.05 & -.18^{* * *} & -.07 & -.05 & -.05\end{array}$

Independent variables

13. Physical Risk-taking

$-\quad-\quad .17^{* * *}-.02$

$\begin{array}{lll}- & - & .00 \quad .04^{* *}\end{array}$

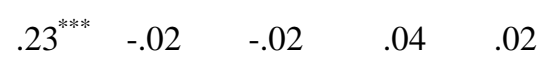

$\begin{array}{llll}3.30 & 0.56 & -.05 & -.02\end{array}$

$\begin{array}{lllllll}-.13^{* *} & .28^{* * *} & -.10^{*} & -.09^{*} & -.23^{* * *} & -.01 & -.04\end{array}$

$\begin{array}{llllllll}.06 & .16^{* * *} & -.02 & -.03 & -.18^{* * *} & -.04 & .06 & -.04\end{array}$

.01

14. Gambling Risk-taking

$\begin{array}{llll}2.81 & 1.22 & .12^{* *} \quad .13^{* *}\end{array}$

$\begin{array}{llllllll}.09^{*} & .20^{* * *} & -.01 & -.11^{* *} & -.17^{* * *} & -.07 & .11^{*} & -.07\end{array}$

$.05 \quad .11^{*}$

Notes. Sex dummy coded male 1, Education dummy coded tertiary education 1 , Student coded $1 . N=548 .{ }^{*} p<.05, * * p<.01$, $* * * p<.001$, 2-tailed. 
Table 3. Regression results by occupational attractiveness

\begin{tabular}{|c|c|c|c|c|c|c|c|c|c|c|}
\hline & \multicolumn{2}{|c|}{$\begin{array}{c}\text { Model } 1 \\
\text { Construction } \\
\underline{\text { Management }}\end{array}$} & \multicolumn{2}{|c|}{$\begin{array}{c}\text { Model } 2 \\
\text { Construction } \\
\text { Management }\end{array}$} & \multicolumn{2}{|c|}{$\begin{array}{c}\text { Model } 3 \\
\text { Architecture }\end{array}$} & \multicolumn{2}{|c|}{$\begin{array}{c}\text { Model } 4 \\
\text { Architecture } \\
\end{array}$} & \multicolumn{2}{|c|}{$\begin{array}{l}\text { Model } 5 \\
\text { Banking }\end{array}$} \\
\hline & S.E. & $\beta$ & S.E. & $\beta$ & S.E. & $\beta$ & S.E. & $\beta$ & S.E. & $\beta$ \\
\hline \multicolumn{11}{|l|}{ Control variables } \\
\hline Age 20-29 & .19 & -.09 & .19 & -.12 & .19 & .14 & .19 & $-.18 *$ & .20 & .03 \\
\hline Age 30-39 & .21 & .08 & .21 & .06 & .21 & -.01 & .21 & -.04 & .22 & .05 \\
\hline Age 50-59 & .24 & .00 & .24 & .01 & .23 & -.05 & .23 & -.05 & .24 & -.06 \\
\hline Age 60-69 & .39 & -.03 & .39 & -.03 & .38 & -.01 & .38 & -.01 & .40 & -.04 \\
\hline Sex & .11 & $.17^{* * *}$ & .11 & $.16 * * *$ & .10 & -.03 & .10 & -.05 & .11 & $.20 * * *$ \\
\hline Education & .15 & -.02 & .15 & -.01 & .15 & .02 & .14 & -.03 & .15 & .06 \\
\hline Student & .11 & -.07 & .11 & -.06 & .11 & -.05 & .11 & -.05 & .11 & $-.13 * *$ \\
\hline Social desirability & .10 & -.04 & .10 & -.05 & .09 & .00 & .09 & -.01 & .10 & .01 \\
\hline \multicolumn{11}{|l|}{ Independent variables } \\
\hline Physical Risk Propensity & & - & .05 & $.13 * *$ & & - & .05 & $.17 * * *$ & .05 & .02 \\
\hline Gambling Risk Propensity & & - & .06 & .02 & & - & .06 & .01 & .07 & $.14^{* *}$ \\
\hline$R$ square & \multicolumn{2}{|c|}{.06} & \multicolumn{2}{|c|}{.08} & \multicolumn{2}{|c|}{.02} & \multicolumn{2}{|c|}{.05} & \multicolumn{2}{|c|}{.10} \\
\hline F statistic & \multirow{2}{*}{\multicolumn{2}{|c|}{$4.49 * * *$}} & \multirow{2}{*}{\multicolumn{2}{|c|}{$\begin{array}{c}4.46^{* * *} \\
.02 * *\end{array}$}} & \multirow{2}{*}{\multicolumn{2}{|c|}{1.34}} & \multirow{2}{*}{\multicolumn{2}{|c|}{$\begin{array}{l}2.71^{* *} \\
.03^{* * *}\end{array}$}} & \multirow{2}{*}{\multicolumn{2}{|c|}{$6.26^{* * *}$}} \\
\hline$\Delta R$ square & & & & & & & & & & \\
\hline
\end{tabular}

Note. Sex dummy coded male 1, Education dummy coded tertiary education 1, Student coded 1. $N=548 .{ }^{*} p<.05$, ** $p<.01$, *** $p<.001$. 
